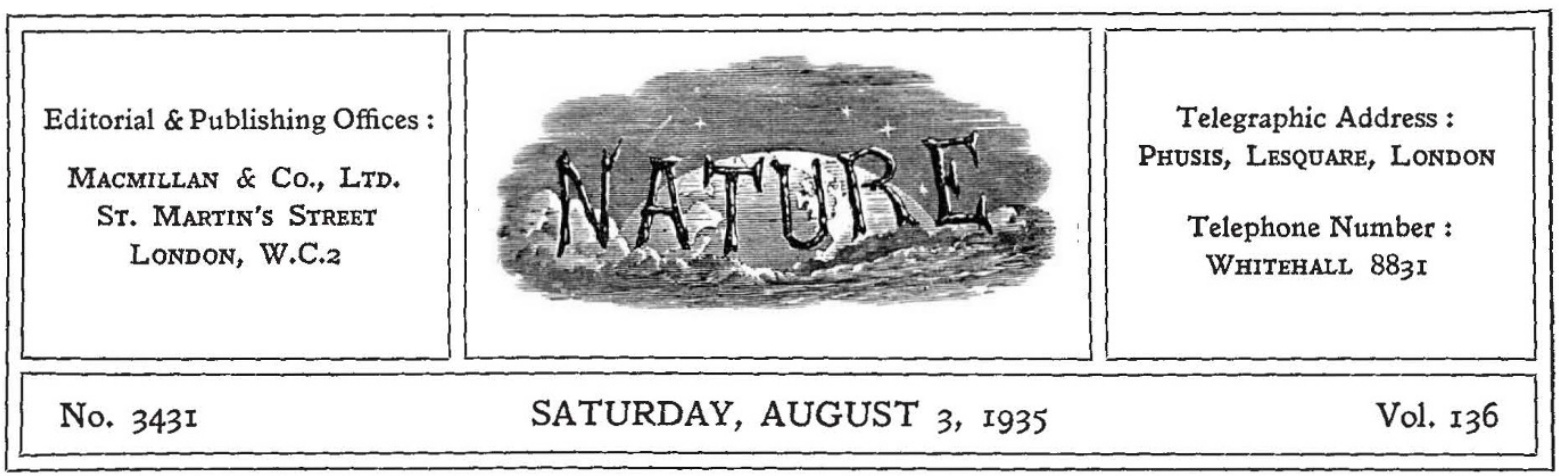

\title{
Problems of Industrial Hygiene
}

$\mathrm{T}$ HE annual reports of the director of the International Labour Organisation cover an extensive field, all the more because the boundaries between social and economic questions have been largely obliterated by the recent economic depression. Hitherto, the main work of the Organisation has lain in the field of protective labour legislation. In this field its activities have already been of direct concern to professional workers, whether in science or elsewhere; and apart from the actual conventions already adopted by the International Labour Conference, a notable amount of research work has been carried out in subjects of direct interest to scientific workers, such, for example, as its studies on the operation of the radius clause, and the problem of the salaried inventor, industrial relations between staff and management, hours of work of professional workers, the status of engineers and chemists, and similar topics.

The extent to which an international labour code has been established has led to the suggestion that the goal of the legislative effort of the Organisation is in sight and that its remaining tasks are secondary. To the examination of this contention, Mr. H. B. Butler devotes a concluding chapter in his recent report (Geneva : International Labour Office, 1935) which is of particular interest to the scientific worker. At the outset, Mr. Butler rightly points out that social legislation is not static but dynamic. Already some of the conventions adopted are becoming out of date. Notably is this true of those bearing on questions of hours of work, in which the growing acceptance of the necessity for some further and wise distribution of employment or leisure is obviously a disturbing factor. Only as proposals are con- tinuously put forward based on assiduous research can we hope to approximate to solutions of such problems which will offer the minimum of distress and the maximum satisfaction of man's needs. There are still important fields for scientific investigation which demand investigators of high quality. Such, for example, are the questions of training for industry, including vocational guidance, apprenticeship and technical education, and the many problems arising out of leisure and the provision of facilities for recreation which were discussed at an international conference at Brussels in June. Besides these, the special problems of the professional worker require fuller consideration, and the fields of industrial hygiene and safety offer an immense scope for future action.

Since the publication by the International Labour Office in 1928 of a report and a supplementary report giving a concise analysis of laws and regulations of all the great industrial countries, as well as a survey of the organisation and activities of safety associations in various countries, and the adoption at the Conference of June 1929 of a draft recommendation concerning the question of industrial accidents, the problems of industrial safety and hygiene have received a growing share of attention in Great Britain and elsewhere. Apart from the purely professional problems of the scientific worker, the work of the International Labour Organisation touches him at no point so closely as at this. Upon his co-operation the success of almost all its efforts in this field finally depends.

The prominence of these questions should not of course be wholly attributed to the influence of the International Labour Organisation. Quite 
independently, the Association of British Chemical Manufacturers has already done a great deal to promote safety and hygiene in chemical industry by means of its model safety rules for chemical works, its safety circulars with their particulars of various accidents and their causes, its 'Safety Summary' of information on accidents and their prevention. The annual reports of H.M. Chief Inspector of Factories record the way in which such matters are receiving increased attention in indus. try generally, and the success of the Industrial Museum at Horseferry Road, Westminster, and the illustrated descriptions of industrial accidents issued quarterly by the Home Office, afford further evidence, if such be needed, of the widespread desire to make conditions in industry as safe and healthy as possible.

Whether we approach the subject from the point of view of the dissemination of information or of that of securing effective action, the part of the scientific worker is equally important. Both in the preparation of summaries or abstracts of safety information, or of such monographs as "Occupation and Health", issued by the International Labour Office, and in their use, his participation is essential if the information provided is first to be accurate and then to be used effectively. There is still need for much wider use and more effective co-ordination of available information, so that experience gained in one firm or industry at the expense of human suffering may be freely available to prevent a similar occurrence elsewhere. Few industries are served so efficiently in this matter as the chemical industry, and the very circulation of such a publication as the Journal of Industrial Hygiene indicates the need for development in this respect.

Again, the participation of scientific workers in the publication of notes on accidents and hazards, their cause and prevention might well be more widely encouraged. Much valuable work is being carried out by various firms, but not all of this is published and made generally available. Moreover, the whole field of industrial hygiene offers opportunities for research which are far from being fully explored. Much work of this type is pre-eminently suited for co-operative effort, and from this point of view the influence of the International Labour Organisation is highly important. While undoubtedly the actual investigations will best be carried out through national organisations, an international organisation can do much to delineate the problems and supply the stimulus where required, as well as secure co-ordination and avoid overlap.

Research work in industrial hygiene demands a high degree of co-operation between various classes of scientific and other professional workers. The annual reports of H.M. Chief Inspector of Factories afford continual evidence that failure to observe the provisions already laid down in the Factory Acts, and consequent industrial accidents, are due to the absence of skilled and qualified supervision, such as that of a chemist or engineer. Still more is it impossible to take adequate precautions and safety measures in the event of unforeseen contingencies, which can scarcely be entirely excluded from some processes or stages of development, in the absence of those who are able to bring a trained mind and expert knowledge to bear on any emergency.

There are welcome signs that this responsibility is now widely recognised among scientific workers, and that those occupying positions of responsibility are resolved to do all in their power to guard the worker in industry from risks of which he is often unaware and which only the scientific worker can appreciate. Certain professional organisations, such as the British Association of Chemists, have set themselves definite aims in this matter, and the Association of British Chemical Manufacturers is already carrying out a large amount of valuable work. The proposals of the new Poison Rules in regard to the supervision of the manufacture of pharmaceutical preparations will certainly be closely scrutinised from this point of view.

There are, however, many industries where a great deal more remains to be done, where scientific and professional workers are isolated and few in number. To raise the standard of industrial hygiene and safety in such industries demands all the support which they can receive from their professional and scientific colleagues and from the investigations and general efforts of such organisations as the International Labour Office. Only as the technical staffs are inspired by the consciousness of high professional traditions and solidarity in this matter of industrial safety, and as the work of the factory inspectors is continually reinforced by educational and research work stimulated by an international organisation pooling knowledge for the common benefit, can we hope to see the minimum standards of the law exchanged for those guaranteeing the maximum security of life and health. 